\title{
Content validation of the symptom control outcome for heart failure patients in palliative care
}

\author{
Validação do resultado controle dos sintomas para pacientes \\ com insuficiência cardíaca em cuidados paliativos \\ Validación de contenido del resultado control de síntomas para \\ pacientes con insuficiencia cardiaca en cuidados paliativos
}

\section{Beatriz Quirino Afonso ${ }^{\mathrm{a}, \mathrm{b}}$ Natany da Costa Ferreira ${ }^{a, c}$ Rita de Cassia Gengo e Silva Butcher ${ }^{\mathrm{a}, \mathrm{d}}$}

\section{How to cite this article:} Afonso BQ, Ferreira NC, Gengo e Silva Butcher RC. Content validation of the symptom control outcome for heart failure patients in palliative care. Rev Gaúcha Enferm. 2020;41:e20190427. doi: https://doi.org/10.1590/19831447.2020.20190427 a Universidade de São Paulo (USP), Escola de Enfermagem, Programa de Pós-Graduação em Enfermagem na Saúde do Adulto. São Paulo, São Paulo, Brasil.

• Instituto do Coração da Faculdade de Medicina da USP. São Paulo, São Paulo, Brasil.

College of Nursing, University of lowa, lowa City, Iwoa, United States of America.

NANDA International-Boston College, The Marjory Gordon Program for Clinical Reasoning an Knowledge Development, Boston, Massachusetts, United States of America.

\section{ABSTRACT}

Objectives: To estimate the content validity of the Symptom Control nursing outcome for heart failure patients in palliative care and to analyze the influence of experts' experience in the judgment of the relevance of indicators.

Methods: A methodological study conducted in São Paulo in 2018, with an adaptation of Fehring's validation model. The relevance of the 11 outcome indicators was assessed by 19 experts by means of an electronically submitted survey. The influence of the experts' experience on judgment was analyzed by the Wilcoxon-Mann-Whitney test and by Kendal's Tau correlation.

Results: The indicators were considered pertinent; with $54.5 \%$ classified as critical. There was no association between the weighted means of the indicators and the experts' experience.

Conclusions: The indicators analyzed are relevant for the evaluation of the Symptom Control outcome in this group of patients. The experts' judgment was not influenced by their area of clinical experience or by their experience with the Nursing Outcomes Classification ( $N O C)$.

Keywords: Symptom assessment. Patient outcome assessment. Standardized nursing terminology. Palliative care. Cardiology.

\section{RESUMO}

Objetivos: Estimar a validade de conteúdo do resultado de enfermagem Controle dos Sintomas para pacientes com insuficiência cardíaca em cuidados paliativos e analisar a influência da experiência dos expertos no julgamento da pertinência dos indicadores.

Métodos: Estudo metodológico conduzido em São Paulo, em 2018, com adaptação do modelo de validação de Fehring. A pertinência dos 11 indicadores do resultado foi avaliada por 19 expertos com instrumento enviado eletronicamente. A influência da experiência dos expertos no julgamento foi analisada pelo teste de Wilcoxon-Mann-Whitney e correlação Tau de Kendall.

Resultados: 0 s indicadores foram considerados pertinentes e $54,5 \%$ classificados como críticos. Não houve associação entre a média ponderada dos indicadores com a experiência dos expertos.

Conclusões: Os indicadores são pertinentes para o resultado Controle dos Sintomas nesse grupo de pacientes. 0 julgamento dos expertos não foi influenciado pela experiência clínica ou experiência com a Classificação de Resultados de Enfermagem (NOC).

Palavras-chave: Avaliação de sintomas. Avaliação de resultados da assistência do paciente. Terminologia padronizada em enfermagem. Cuidados paliativos. Cardiologia.

\section{RESUMEN}

Objetivos: Estimar la validación de contenido del resultado de enfermería Control de síntomas para pacientes con insuficiencia cardíaca en cuidados paliativos y analizar la influencia de la experiencia de los expertos para determinar la relevancia de los indicadores. Métodos: Estudio metodológico realizado en San Pablo en el año 2018, con una adaptación del modelo de validación de Fehring. La relevancia de los 11 indicadores de resultados fue evaluada por 19 expertos por medio de un instrumento enviado electrónicamente. La influencia de la experiencia de los expertos en las determinaciones se analizó mediante la prueba de Wilcoxon-Mann-Whitney y la correlación Tau de Kendall.

Resultados: Los indicadores se consideraron pertinentes; con el 54,5\% clasificados como críticos. No hubo asociación entre las medias ponderadas de los indicadores y la experiencia de los expertos.

Conclusión: Los indicadores analizados son relevantes para evaluar el resultado Control de síntomas en este grupo de pacientes. La determinación de los expertos no se vio influenciada por su experiencia clínica ni por su experiencia con la Clasificación de Resultados de Enfermería (Nursing Outcomes Classification, NOC).

Palabras clave: Evaluación de síntomas. Evaluación del resultado de la atención al paciente. Terminología normalizada de enfermería. Cuidados paliativos. Cardiología. 


\section{口INTRODUCTION}

Heart Failure (HF) is recognized for its high incidence and prevalence rates worldwide ${ }^{(1)}$, as well as for the high cost associated with its treatment. It is considered a complex clinical syndrome, characterized by a range of signs and symptoms caused by structural and functional changes in the heart that result in decreased cardiac output or in increased intracardiac pressures ${ }^{(1)}$.

Therapeutic advancements have improved the survival rates of HF patients. However, they are not enough over time to prevent progression of the disease ${ }^{(2)}$. The progress of HF is marked by the occurrence of disabling physical and emotional symptoms, multiple episodes of exacerbations, functional decline, changes in social roles, and the need for repeated hospital admissions ${ }^{(3)}$, culminating in severely compromised quality of life ${ }^{(4)}$.

Admittedly, the burden of symptoms associated with $\mathrm{HF}$ is comparable to or exceeds that seen in patients with cancer ${ }^{(5)}$. A study showed that HF patients in their last week of life have uncontrolled symptoms ${ }^{(5)}$. In this scenario, the Palliative Care (PC) approach in the management of HF patients has been recommended by different consensus and guidelines ${ }^{(1)}$. There is evidence that such an approach improves the health outcomes of HF patients in terms of quality of life, symptom control, and rehospitalizations, among others ${ }^{(3)}$.

Symptom control is one of the objectives of $\mathrm{PC} \mathrm{C}^{(4)}$. However, symptom assessment still remains a challenge. On one hand, the professionals fail to ask the right questions for investigating the symptoms; on the other hand, the patients tend to minimize their suffering ${ }^{(2)}$. Additionally, despite the different scales available for symptom assessment, many have been developed for use in research and are difficult to apply in the daily clinical practice ${ }^{(2)}$.

The Edmonton Symptom Assessment Scale (ESAS) is a scale with good evidence of validity for use in the clinical practice and has a good correlation with non-classical HF symptoms and with global measures of the health status of these patients ${ }^{(6)}$. However, the ESAS scale is restricted to assessing the intensity of 10 symptoms (pain, fatigue, nausea, depression, anxiety, drowsiness, appetite, and dyspnea, among other symptoms). A more comprehensive assessment of the onset, frequency, persistence, severity, and perception of symptom control, as well as the use of available strategies to alleviate them, can more effectively contribute to inform professionals in clinical practice and research on the effectiveness of the interventions, because they go beyond the exclusive measurement of the burden of the symptoms.
For the most comprehensive assessment of symptom control, the outcome indicators proposed by the Nursing Outcome Classification (NOC) can be useful( ${ }^{(7)}$. The NOC is a language standardization of patient outcomes sensitive to the interventions implemented by the health team. It was proposed by nurses and has been used predominantly by these professionals in teaching, research, and care. In the fifth edition of the NOC, there are 490 approved outcomes, among which the Symptom Control (1608) nursing outcome is defined as "personal actions to minimize perceived adverse changes in the physical and emotional functions" $(7)$.

Various authors have demonstrated the benefits of using the NOC in the clinical practice. In an integrative review, Silva, Oliveira and Carvalho verified that the NOC is a tool that allows for the standardization and individualization of anamnesis; assists in characterizing the health status of the patients; contributes to the establishment of care goals; is useful for assessing the impact, quality, and effectiveness of the implemented interventions; and helps to identify areas where the nurses' performance needs to be improved ${ }^{(8)}$.

More recently, Lee suggested that the use of the NOC can be an important ally to improve the aspects related to patient safety ${ }^{(9)}$. Other authors verified that the NOC outcomes and their indicators were able to capture the changes in the clinical evolution of cancer patients in palliative care ${ }^{(10)}$.

No studies have been found that have evaluated evidences of the validity of the Symptom Control (1608) NO from the NOC. Considering the relevance of symptom assessment in $\mathrm{HF}$ patients in $\mathrm{PC}$, the need to have more comprehensive instruments for the assessment of symptom control and the lack of validity estimates for this NO of the NOC, the present study aimed to estimate the content validity of the Symptom Control (1608) NO for HF patients in palliative care, as well as to analyze the influence of the experts' experience in the judgment on the pertinence of the indicators.

\section{$\square$ METHOD}

This is a methodological study of content validation whose data collection was conducted from February to May 2018. The convenience sample consisted of expert members of research groups registered in the directory of research groups of the Brazilian National Council for Scientific and Technological Development (CNPq). The search terms used to locate the groups were "nursing in cardiology", "nursing in palliative care", and "palliative care". The snowball type sample was also used ${ }^{(11)}$

The study inclusion criterion was the following: nurses with clinical experience of at least two years in the field of 
cardiovascular nursing and/or palliative care, as described in the curriculum registered on the CNPq Lattes platform. Other criteria established in the literature were not adopted due to the reduced availability of experts who met the suggested criteria $^{(12-13)}$. The nurses who did not return the data collection instrument filled in within the stipulated time or who did not complete the instrument as directed were excluded.

The experts who met the inclusion criteria were invited by email to participate in the study. Those who accepted the invitation received the Free and Informed Consent Form (FICF) and the data collection instrument. Demographic, academic, and professional characterization data were collected.

For content validation, the method proposed by Fehring adapted for the validation of $\mathrm{NOS}^{(14)}$ was used, and a specific instrument was developed with the definition of the NOC for the Symptom Control (1608) NO and all the indicators with respective conceptual definitions previously validated by the authors of the present study ${ }^{(15)}$.

The experts were requested to analyze the degree of pertinence of each indicator to measure the NO in HF patients in PC using a 5-point Likert scale, where: 1- not pertinent at all, 2- little pertinent, 3- moderately pertinent, 4- very pertinent, and 5 - extremely pertinent. The experts were asked to provide justifications for their answers when they considered that the indicator was not pertinent at all or little pertinent. There was space for the experts to make other comments that they deemed necessary.

They had 15 days to return the completed data collection instrument, a time limit that could be extended for another five days. At the end of this period, those who did not return the completed instrument, or who did not complete it properly, were excluded from the study.

The quantitative variables of demographic, academic, and professional characterization were described by measures of central tendency and dispersion; and the categorical variables, by means of their absolute and relative frequencies. To estimate the pertinence of each indicator to the $\mathrm{NO}$, each point on the Likert scale was assigned a weight, namely: $1=0$; $2=0.25 ; 3=0.50,4=0.75$; and $5=1$, which was used to calculate the weighted mean. The indicators were classified as critical (mean $>0.80$ ), supplementary (mean $>0.50$ and $<0.80$ ), and not necessary, with a mean $<0.50^{(12)}$.

To analyze the influence of the experts' experience in the judgment on the pertinence of the indicators to the NO, the Wilcoxon-Mann-Whitney test was used to compare the weighted means of the indicators according to clinical experience only in one specialty (cardiovascular nursing or PC) or in both. Kendall's tau correlation test was used to analyze the correlation between the weighted means of the indicators with the self-reported experience with the NOC in care, teaching, and research. p-values were considered significant when $<0.05$.

This study was conducted based on the ethical precepts of Resolution 466/2012 of the National Health Council of the Brazilian Ministry of Health. The study was approved by the Research Ethics Committee (opinion number 2,490,650). All the participants signed the FICF.

\section{RESULTS}

Seventy-two nurses were invited to participate in the study, of which 36 did not respond and six refused the invitation. Of the 30 experts who received the data collection instrument, 11 were excluded (seven did not return it on time and four did not complete it as directed).

Therefore, the sample consisted of 19 experts, with a mean age of $39.7+9.0$ years old. There was a predominance of female experts ( $n=17 ; 89.5 \%)$. As for their highest academic degree, $47.4 \%(n=9)$ were PhDs, 26.3\% $(n=5)$ were specialists, $21.1 \%(n=4)$ were masters, and $5.3 \%(n=1)$ had a post-doctoral degree. Most of the experts $(n=13 ; 68.4 \%)$ had experience in only one of the specialties, with a mean time of experience in cardiovascular nursing of $9.2+5.8$ years, and of $2.3+3.2$ years in PC. It was verified that $73.7 \%(n=14)$ worked in teaching, 63.1\% $(n=12)$ in research, and $52.6 \%(n=10)$ in care.

Table 1 shows the level of self-reported experience of the experts regarding the use of the nursing process, of standardized language systems, and of the NOC in particular, in care, teaching, and research.

Table 2 shows the weighted mean of the degree of pertinence of the indicators of the Symptom Control (1608) NO.

Table 3 analyzes the pertinence of the indicators and the respective mean and standard deviation values according to the experts> cardiovascular and/or PC experience.

Table 4 shows the correlation between the weighted mean values of the Symptom Control NO according to the degree of experience in using the NOC in care, teaching, and research.

There were no statistically significant differences between the weighted means of the indicators according to clinical experience in only one specialty or in both (Table 3). There was also no correlation between the weighted means of each indicator with the experience in using the NOC in care, teaching, and research (Table 4). 
Table 1 - Self-reported experience of the experts $(n=19)$ in the use of the nursing process and of standardized language systems in care, teaching, and research. São Paulo, SP, Brazil, 2018

\begin{tabular}{lcccc} 
Experience & $\begin{array}{c}\text { None } \\
\mathbf{n}(\%)\end{array}$ & $\begin{array}{c}\text { Little } \\
\mathbf{n}(\%)\end{array}$ & $\begin{array}{c}\text { Reasonable } \\
\mathbf{n}(\%)\end{array}$ & $\begin{array}{c}\text { Very much } \\
\mathbf{n}(\%)\end{array}$ \\
Use of the nursing process & & & & \\
In care & $0(0.0)$ & $3(15.79)$ & $3(15.79)$ & $13(68.42)$ \\
In teaching & $1(5.26)$ & $3(15.79)$ & $6(31.58)$ & $9(47.37)$ \\
In research & $2(10.53)$ & $5(26.31)$ & $6(31.58)$ & $6(31.58)$ \\
Use of standardized language & & & & \\
In care & $0(0.0)$ & $4(21.05)$ & $4(21.05)$ & $11(57.90)$ \\
In teaching & $3(15.79)$ & $1(5.26)$ & $6(31.58)$ & $9(47.37)$ \\
In research & $1(5.26)$ & $4(21.05)$ & $6(31.58)$ & $8(42.11)$ \\
Use of the Nursing & & & & \\
Outcomes Classification & & & & \\
In care & $6(31.58)$ & $4(21.05)$ & $9(47.37)$ & $0(0.0)$ \\
In teaching & $3(15.79)$ & $7(36.84)$ & $7(36.84)$ & $2(10.53)$ \\
In research & $4(21.05)$ & $8(42.11)$ & $6(31.58)$ & $1(5.26)$ \\
\hline
\end{tabular}

Source: Research data, 2018

Table 2 - Weighted mean of the degree of pertinence of the critical and supplementary indicators of the Symptom Control (1608) outcome according to the experts' opinion $(n=19)$ for heart failure patients in palliative care. São Paulo, SP, Brazil, 2018

Indicators

Weighted mean

\section{Critical indicators}

160802 - Monitors symptom persistence $\quad 0.91$

160801 - Monitors symptom onset $\quad 0.88$

160804 - Monitors symptom frequency $\quad 0.87$

$\mathbf{1 6 0 8 1 3}$ - Obtains health care when warning signs occur $\quad 0.86$

160803 - Monitors symptom severity $\quad 0.84$

160806 - Uses preventive measures $\quad 0.84$

Supplementary indicators

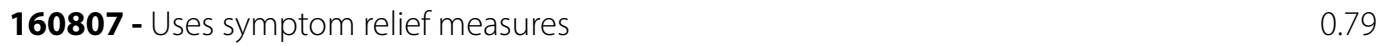

160809 - Uses available resources $\quad 0.79$

160805 - Monitors symptom variation $\quad 0.76$

160811 - Reports symptoms controlled 0.76

160810 - Uses diary to monitor symptoms over time $\quad 0.72$

Source: Research data, 2018 
Table 3 - Analysis of the pertinence of the indicators, mean (standard deviation), of the Symptom Control (1608) outcome according to the clinical experience of the experts in only one specialty or in both. São Paulo, SP, Brazil, 2018

\begin{tabular}{lccc} 
& \multicolumn{1}{c}{ Weighted means } & p-value \\
\cline { 2 - 3 } Indicators & $\begin{array}{c}\text { Experience in only one } \\
\text { of the specialties }\end{array}$ & $\begin{array}{c}\text { Experience in both } \\
\text { specialties }\end{array}$ & -val \\
$\mathbf{1 6 0 8 0 2}$ - Monitors symptom persistence & $0.92(0.13)$ & $0.93(0.16)$ & 0.65 \\
$\mathbf{1 6 0 8 0 1}$ - Monitors symptom onset & $0.91(0.13)$ & $0.90(0.17)$ & 0.96 \\
$\mathbf{1 6 0 8 0 4}$ - Monitors symptom frequency & $0.88(0.15)$ & 0.33 \\
$\mathbf{1 6 0 8 1 3}$ - Obtains health care when & $0.86(0.13)$ & $0.16)$ & 0.24 \\
warning signs occur & $0.89(0.13)$ & $0.83(0.20)$ & 0.56 \\
$\mathbf{1 6 0 8 0 3}$ - Monitors symptom severity & $0.81(0.21)$ & $0.93(0.16)$ & 0.18 \\
$\mathbf{1 6 0 8 0 6}$ - Uses preventive measures & $0.90(0.15)$ & $0.87(0.21)$ & 0.75 \\
$\mathbf{1 6 0 8 0 7}$ - Uses symptom relief measures & $0.90(0.15)$ & $0.87(0.21)$ & 0.75 \\
$\mathbf{1 6 0 8 0 9}$ - Uses available resources & $0.83(0.18)$ & $0.77(0.23)$ & 0.56 \\
$\mathbf{1 6 0 8 0 5}$ - Monitors symptom variation & $0.85(0.20)$ & $0.73(0.16)$ & 0.25 \\
$\mathbf{1 6 0 8 1 1}$ - Reports symptoms controlled & $0.77(0.21)$ & $0.80(0.18)$ & 0.78 \\
$\mathbf{1 6 0 8 1 0}$ - Uses diary to monitor symptoms \\
over time
\end{tabular}

Source: Research data, 2018.

\section{DISCUSSION}

In this study, the content validity was estimated of the Symptom Control (1608) NO from the NOC for HF patients in PC. There is no consensus in the literature on the sample size in content validation studies. The authors agree that samples from five to 10 experts would be sufficient to know the judgment, as well as to reach an agreement on a specific topic ${ }^{(16-17)}$.

Considering that in validation studies the experts must have knowledge about the phenomenon under investigation ${ }^{(18-19)}$, it was decided to select experts with clinical experience in cardiovascular nursing and/or PC. Despite the efforts to obtain an equivalent number of experts with experience in both areas, a greater number of experts with clinical experience in cardiovascular nursing participated in the study, which can be explained by the fact that PC is a new specialty in the health area ${ }^{(20)}$.
Clinical experience in one or both specialties, however, did not influence the analysis of the pertinence of the indicators to the NO. This finding can be explained in terms of the clinical experience in caring for patients with heart diseases and in palliative care, and also by the availability of the conceptual and operational definitions of the indicators. The literature demonstrates that the use of conceptual and operational definitions improves intra-evaluator agreement when pairs of nurses evaluate the same patient ${ }^{(21)}$.

Still in terms of knowledge about the object under investigation, the self-reported experience of the experts in relation to the use of the NOC is similar to that observed in other studies ${ }^{(19,22)}$. However, it should be highlighted that if, on the one hand, the clinical experience of the experts in the use of the NOC in care is still incipient, on the other, they considered themselves experienced in the use of the nursing process and of standardized language systems in general in the three areas of performance. 
Table 4 - Correlation between the weighted means of the indicators of the Symptom Control (1608) outcome with the degree of self-reported experience in using the Nursing Outcomes Classification in care, teaching, and research. São Paulo, SP, Brazil, 2018

\begin{tabular}{|c|c|c|c|c|c|c|}
\hline \multirow{2}{*}{ Indicators } & \multicolumn{2}{|c|}{$\begin{array}{c}\text { Experience in the use of } \\
\text { the NOC in care }\end{array}$} & \multicolumn{2}{|c|}{$\begin{array}{l}\text { Experience in the use of } \\
\text { the NOC in teaching }\end{array}$} & \multicolumn{2}{|c|}{$\begin{array}{l}\text { Experience in the use of } \\
\text { the NOC in research }\end{array}$} \\
\hline & Correlation & p-value & Correlation & p-value & Correlation & p-value \\
\hline $\begin{array}{l}160802 \text { - } \\
\text { Monitors } \\
\text { symptom persistence }\end{array}$ & -0.150 & 0.49 & 0.01 & 0.96 & 0.093 & 0.66 \\
\hline $\begin{array}{l}160801 \text { - } \\
\text { Monitors symptom onset }\end{array}$ & -0.1116 & 0.59 & 0.010 & 0.96 & 0.112 & 0.60 \\
\hline $\begin{array}{l}160804 \text { - } \\
\text { Monitors } \\
\text { symptom frequency }\end{array}$ & -0.067 & 0.75 & 0.037 & 0.86 & 0.157 & 0.46 \\
\hline $\begin{array}{l}\mathbf{1 6 0 8 1 3} \text { - } \\
\text { Obtains health care when } \\
\text { warning signs occur }\end{array}$ & 0.085 & 0.70 & 0.270 & 0.21 & 0.337 & 0.12 \\
\hline $\begin{array}{l}160803 \text { - } \\
\text { Monitors symptom severity }\end{array}$ & -0.207 & 0.33 & -0.060 & 0.78 & 0.174 & 0.41 \\
\hline $\begin{array}{l}160806 \text { - } \\
\text { Uses preventive measures }\end{array}$ & 0.100 & 0.63 & 0.043 & 0.83 & -0.070 & 0.74 \\
\hline $\begin{array}{l}\mathbf{1 6 0 8 0 7 -} \\
\text { Uses symptom } \\
\text { relief measures }\end{array}$ & -0.364 & 0.09 & -0.125 & 0.55 & -0.078 & 0.71 \\
\hline $\begin{array}{l}160809 \text { - } \\
\text { Uses available resources }\end{array}$ & -0.364 & 0.09 & -0.125 & 0.55 & $-0,078$ & 0.71 \\
\hline $\begin{array}{l}160805 \text { - } \\
\text { Monitors symptom variation }\end{array}$ & -0.043 & 0.84 & -0.122 & 0.55 & 0.074 & 0.72 \\
\hline $\begin{array}{l}\mathbf{1 6 0 8 1 1 ~ - ~} \\
\text { Reports } \\
\text { symptoms controlled }\end{array}$ & -0.711 & 0.07 & -0.129 & 0.53 & -0.147 & 0.47 \\
\hline $\begin{array}{l}\mathbf{1 6 0 8 1 0} \text { - } \\
\text { Uses diary to monitor } \\
\text { symptoms over time }\end{array}$ & -0.084 & 0.69 & 0.185 & 0.36 & 0.310 & 0.132 \\
\hline
\end{tabular}

Source: Research data, 2018.

NOC = Nursing Outcomes Classification

This result can be explained, at least in part, due the clinical reasoning skills that the experts built throughout their training and professional trajectory. It is known that clinical reasoning is a process that allows and encourages the construction of new knowledge from previously acquired experience and knowledge ${ }^{(23)}$. Thus, it is believed that the experience in the use of other types of standardized language, in addition to clinical experience, contributed to the experts' assessment of the relevance of the NOC indicators for this group of patients.

In fact, the use of the NOC is not yet widespread in clinical health care settings, compared to other systems for 
classifying nursing phenomena ${ }^{(22)}$. Despite this, it has been demonstrated that the NOC outcomes are useful for measuring patient outcomes after a nursing intervention and/or by other health professionals ${ }^{(24-25)}$. It was observed that the degree of self-reported experience in the use of the NOC, however, did not influence the analysis of the pertinence of the NO indicators.

Unlike other outcome or goal measures, the NOC has the purpose of measuring the outcome in a continuum of health, which can be an advantage over other instruments available to assess symptom contro| ${ }^{(7)}$. Another advantage of the Symptom Control (1608) NO from the NOC is that it provides a multidimensional measure of symptoms $s^{(7)}$ and, therefore, a more comprehensive assessment than available instruments that only assess the intensity of symptoms ${ }^{(26)}$. In other words, the measure of this NO includes attributes related to the management of symptoms (for example, the Uses preventive measures and Uses symptom relief measures) indicators, in addition to those strictly related to the symptoms themselves ${ }^{(7)}$, such as the Monitors symptom onset and Monitors the symptom persistence indicators.

The theoretical model of self-care based on the theory of unpleasant symptoms suggests that the symptoms explain the association between the severity of the disease and self-care, so that the management of symptoms in HF patients can mediate the improvement of self-care ${ }^{(27)}$. In this perspective, the management of symptoms precedes the improvement of self-care, and not the other way around. This reinforces the importance of having measures that are capable of capturing changes in the management or control of symptoms in the continuum of health care.

The findings of the present study corroborated the pertinence of the 11 indicators to the NO proposed by the NOC for HF patients in PC. Knowing the pertinence of the indicators to a specific group of patients is important because not all the NOC indicators need to be evaluated to measure an outcome. Recently, a number of authors estimated the content validation of two NOs on knowledge and self-control of diabetes in people with the disease. Through the opinion of 16 experts, they identified that, among 80 indicators of both NOs, 73 were considered critical(9).

In fact, the NOC outcome indicators are comprehensive enough to cover the entire life cycle and health or disease conditions. Thus, the type of health problem, the medical condition, the patient's characteristics, the available resources, and the potential treatment must be taken into account in the nurse's clinical decision-making ${ }^{(7)}$.

In order to estimate differences in the degree of pertinence of the indicators, the weighted mean value was used to categorize them into critical, supplementary, and not necessary. All the indicators were considered pertinent. The set of critical indicators evidenced the outcome attributes related to the recognition and the ability to monitor changes in the symptoms, the use of preventive measures, and the search for health care in the presence of warning signs. In turn, the set of secondary indicators gathers the outcome attributes that characterize the willingness or ability to use resources to control the symptoms.

Interestingly, there seems to be a relationship between the critical and supplementary indicators with two of the three constructs described in the theory of self-care in HF. In this theory, the authors define self-care as a naturalistic decision-making process that maintains physiological stability, facilitates perception, and guides the management of symptoms ${ }^{(28)}$.

The critical indicators, identified in the present study, are in line with the construct of symptom perception, which involves the detection and interpretation of physical sensations. The secondary indicators are congruent with the management construct, which deals with the response to the symptoms when they occur. In this study, the Symptom Control (1608) NO could be used as an objective measure of these constructs. None of the indicators of this $\mathrm{NO}$ seems to correspond to the first construct of the theory, which deals with adherence behaviors.

\section{CONCLUSION}

When performing the content validation of the Symptom Control (1608) nursing outcome, it was verified that all 11 indicators proposed by the NOC are pertinent for the evaluation of this outcome in HF patients in PC. There was no influence of the clinical experience or of the degree of experience in the use of the $\mathrm{NOC}$ in judging the pertinence of the indicators in relation to the NO.

This study contributes to the care practice because it allows for a multidimensional assessment of symptom control, which is an advancement in terms of other instruments available in the literature. For nursing research, the findings are important because they provide an estimate of a valid measure to evaluate symptom control. As the indicators represent concrete and measurable $\mathrm{NO}$ measures, the findings can also be taught to nursing students and professionals.

As limitations, it should be considered that the convenience sample for selecting expert nurses compromises the external validation of the results. In addition, it is not possible to generalize the results of the pertinence analysis to other groups of patients, since only symptom control was considered in the palliative care scenario for HF patients. Studies are needed aimed at estimating the clinical validity, as well as other psychometric measures of the indicators. 


\section{REFERENCES}

1. Ponikowski P, Voors AA, Anker SD, Bueno H, Cleland JGF, Coats AJS, et al. 2016 ESC Guidelines for the diagnosis and treatment of acute and chronic heart failure. The Task Force for the diagnosis and treatment of acute and chronic heart failure of the European Society of Cardiology (ESC) Developed with the special contribution of the Heart Failure Association (HFA) of the ESC. Eur Heart J. 2016;37(27):2129-200. doi: https://doi.org/10.1093/eurheartj/ehw128

2. Alpert CM, Smith MA, Hummel SL, Hummel EK. Symptom burden in heart failure: assessment, impact on outcomes, and management. Heart Fail Rev. 2017;22(1):25-39. doi: https://doi.org/10.1007/s10741-016-9581-4

3. Hritz CM. Palliative therapy in heart failure. Heart Fail Clin. 2018;14(4):617-24. doi: https://doi.org/10.1016/j.hfc.2018.06.011

4. Mcllvennan CK, Allen LA. Palliative care in patients with heart failure. BMJ. 2016;353:i1010. doi: https://doi.org/10.1136/bmj.i1010

5. Årestedt K, Alvariza A, Boman K, Öhlén J, Goliath I, Håkanson C, et al. Symptom relief and palliative care during the last week of life among patients with heart failure: a national register study. J Palliat Med. 2018;21(3):361-7. doi: https:// doi.org/10.1089/jpm.2017.0125

6. Ezekowitz JA, Thai V, Hodnefield TS, Sanderson L, Cujec B. The correlation of standard heart failure assessment and palliative care questionnaires in a multidisciplinary heart failure clinic. J Pain Symptom Manage. 2011;42(3):37987. doi: https://doi.org/10.1016/j.jpainsymman.2010.11.013

7. Moorhead S, Johnson M, Maas ML, Swanson E. Classificação de resultados de enfermagem (NOC). 5. ed. Rio de Janeiro: Elsevier; 2016

8. Silva NC, Oliveira AR, Carvalho EC. Knowledge produced from the outcomes of the "Nursing Outcomes Classification - NOC": integrative review. Rev Gaúcha Enferm. 2015;36(4):104-11 doi: https://doi.org/10.1590/1983-1447.2015.04.53339

9. Lee E. Use of the Nursing Outcomes Classification for falls and fall prevention by nurses in South Korea. Int J Nurs Knowl. 2019;30(1):28-33. doi: https://doi. org/10.1111/2047-3095.12201

10. Mello BS, Massutti TM, Longaray VK, Trevisan DF, Lucena AF. Applicability of the Nursing Outcomes Classification (NOC) to the evaluation of cancer patients with acute or chronic pain in palliative care. Appl Nurs Res. 2016;29:12-8. doi: https://doi.org/10.1016/j.apnr.2015.04.001

11. Polit DF, Beck CT. Fundamentos de pesquisa em enfermagem: avaliação de evidências para a prática da enfermagem. 7. ed. Porto Alegre: Artmed; 2011.

12. Fehring R. Methods to validate nursing diagnosis. Heart Lung.1987;16(6):625-9.

13. Guimarães HC, Pena SB, Lopes JL, Lopes CT, Barros AL. Experts for validation studies in nursing: new proposal and selection criteria. Int J Nurs Knowledge. 2016;27(3):125-80. doi: https://doi.org/10.1111/2047-3095.12089

14. Oh H, Moorhead S. Validation of the knowledge and self-management nursing outcomes classification for adults with diabetes. Comput Inform Nurs. 2018;37(4):222-8. doi: https://doi.org/10.1097/CIN.0000000000000495

15. Afonso BQ, Ferreira NC, Butcher RCG. Definiciones conceptuales y operacionales de los indicadores del resultado Control de Síntomas para pacientes con insuficiencia cardíaca en cuidados paliativos. Enferm Clin. 2020. doi: https:// doi.org/10.1016/j.enfcli.2020.01.001 In Press. Corrected proof.

\section{- Corresponding author:}

Beatriz Quirino Afonso

Email: Beatriz.afonso@usp.br

Received: 11.24 .2019

Approved: 03.06.2020
16. Lynn MR. Determination and quantification of content validity. Nurs Res. 1986;35(6):382-6. doi: https://doi. org/10.1097/00006199-198611000-00017

17. Polit DF, Beck CT. The content validity index: are you sure you know what's being reported? Critique and recommendations. Res Nurs Health. 2006;29(5):489-97. doi: https://doi.org/10.1002/nur.20147

18. Moreira RP, Araujo LT, Cavalcante TF, Guedes NG, Costa AG, Lopes MV. Validation of the mobility nursing outcome in stroke survivors. Int J Nurs Knowl. 2013;24(3):157-62. doi: https://doi.org/10.1111/j.2047-3095.2013.01245.x

19. Lucena AF, Argenta C, Almeida MA, Moorhead S, Swanson E. Validation of Nursing Outcomes and Interventions to older adults care with risk or frail elderly syndrome: proposal of linkages among NOC, NIC, and NANDA-I to clinical practice. Int J Nurs Knowl 2018;30(3):147-53. doi: https://doi. org/10.1111/2047-3095.12225

20. Viana GKBV, Silva HÁ, Lima AKGL, Lima ALAL, Mourão CML, Freitas ASF, et al. [Educational intervention in the nursing team beyond palliative care]. J. Health Biol Sci (Online). 2018 6(2):165-9. Portuguese. doi: https://doi. org/10.12662/2317-3076jhbs.v6i2.1458.p165-169.2018

21. Monteiro FPM, Araujo TL, Costa FBC, Leandro TA, Cavalcante TF, Lopes MVO. Clinical validation of nursing diagnosis "Willingness for improved infant development". Rev Bras Enferm. 2016;69(5):802-9. doi: https://doi. org/10.1590/0034-7167-2015-0131

22. D’Agostino F, Zeffiro V, Vellone E, Ausili D, Belsito R, Leto A, et al. Cross-mapping of nursing care terms recorded in Italian hospitals into the Standardized NNN Terminology. Int J Nurs Knowl. 2020;31(1):4-13. doi: https://doi. org/10.1111/2047-3095.12200

23. Holder AG. Clinical reasoning: a state of the science report. Int J Nurs Educ Scholarsh. 2018;15(1):20160024. doi: https://doi.org/10.1515/ ijnes-2016-0024

24. Vázquez-Sánchez MA, Valero-Cantero I, Carrión-Velasco Y, Castro-López P, Suárez-Cadenas E, Casals C. Applicability and clinical validity of Nursing Outcomes Classification in a nursing intervention of nutritional counseling for patients with malnutrition. Int J Nurs Terminol Knowl. 2019;30(3):168-72. doi: https://doi.org/10.1111/2047-3095.12224

25. Mello BS, Massutti TM, Longaray VK, Trevisan DF, Lucena AF. Applicability of the Nursing Outcomes Classification (NOC) to the evaluation of cancer patients with acute or chronic pain in palliative care. Appl Nurs Res. 2016;29:12-8. doi: https://doi.org/10.1016/j.apnr.2015.04.001

26. Monteiro DR, Almeida MA, Kruse MHL. Translation and cross-cultural adaptation of the Edmonton Symptom Assessment System for use in Palliative Care. Rev Gaúcha Enferm. 2013;34(2):163-71. doi: https:/doi.org/10.1590/ s1983-14472013000200021

27. Yang IS, Kang Y. Self-care model based on the theory of unpleasant symptoms in patients with heart failure. Appl Nurs Res. 2018;43:10-7. doi: https://doi. org/10.1016/j.apnr.2018.06.005

28. Riegel B, Dickson VV, Faulkner KM. The Situation-specific theory of heart failure self-care: revised and updated. J Cardiovasc Nurs. 2016;31(3):226-35. doi: https://doi.org/10.1097/JCN.0000000000000244

\section{Associate editor:}

Cecília Helena Glanzner

\section{Editor-in-chief:}

Maria da Graça Oliveira Crossetti 